\title{
Establishment and Application of Digital RT-PCR Assay for Detection of Avian Influenza Virus H9 Subtype
}

\author{
Bin $W^{1}{ }^{*}$, Lin Zhang1, Liming Su${ }^{2}$, Huijun Zhao', Xiaoping Cai ${ }^{1}$ \\ ${ }^{1}$ Liaoning Entry-Exit Inspection and Quarantine Bureau, Dalian, China \\ ${ }^{2}$ China Certification \& Inspection Group Liaoning Co. Ltd., Dalian, China \\ Email: *wubin69@163.com
}

How to cite this paper: $\mathrm{Wu}, \mathrm{B}$., Zhang, L., Su, L.M., Zhao, H.J. and Cai, X.P. (2017) Establishment and Application of Digital RT-PCR Assay for Detection of Avian Influenza Virus H9 Subtype. Advances in Microbiology, 7, 760-768.

https://doi.org/10.4236/aim.2017.711061

Received: October 9, 2017

Accepted: November 25, 2017

Published: November 28, 2017

Copyright $\odot 2017$ by authors and Scientific Research Publishing Inc. This work is licensed under the Creative Commons Attribution International License (CC BY 4.0).

http://creativecommons.org/licenses/by/4.0/

\section{(c) (i) Open Access}

\begin{abstract}
A digital RT-PCR method for rapid detection of H9 subtype influenza was established by comparing the two methods of digital RT-PCR and real-time quantitative RT-PCR. The sensitivity, specificity and reproducibility of the two methods for $\mathrm{H} 9$ were determined by gradient dilution using the same pair of primers and probes. Both methods were able to detect $10^{4}$ times diluted H9 pathogens, while digital RT-PCR could detect H9 in single droplets, and its sensitivity was higher than real-time quantitative RT-PCR. At the same time, the specificities of both methods were very strong, with no amplification reactions for H3N2, H4N2, H6N2. The reproducibility of the two methods were also good. Digital RT-PCR has a higher sensitivity than real-time quantitative RT-PCR and could play an important role in the rapid detection of H9 subtype influenza virus.
\end{abstract}

\section{Keywords}

Avian Influenza Virus H9 Subtype (H9), Digital RT-PCR, Real-Time Quantitative RT-PCR, Sensitivity, Specificity

\section{Introduction}

Avian influenza (AI) is a highly contagious avian influenza disease caused by the orthomyxovirus class A influenza virus, with 16 HA subtypes and 10 NA subtypes [1]. According to the avian influenza virus (Avian influenza virus, AIV), pathogenicity can be divided into highly pathogenic avian influenza and low pathogenic avian influenza virus [2]. H9 subtype low pathogenic AIV (hereinafter referred to as H9) is widely found in China's Liaoning, Anhui, Shandong, 
Guangdong, Fujian, Jiangsu, Henan, Hunan, Hubei, Shanghai, Guangxi, Yunnan, Sichuan, Xinjiang and other regions [3], so it is very important to detect and diagnose it.

As a novel nucleic acid detection method, digital PCR (dPCR) technology independently performs PCR reactions by dividing the reaction system into a large number of reaction units and calculating the number of nucleic acids according to the Poisson distribution and the positive ratio [4].

Currently, there are two kinds of digital PCR tests, droplets and chip. Unlike traditional quantitative PCR techniques, dPCR is independent of the circulatory threshold (CT) of the amplification curve and is not affected by amplification efficiency, with good accuracy and reproducibility, and can achieve absolute quantitative analysis [5]. In this paper, dRT-PCR was established by comparing the sensitivity, specificity and reproducibility of dRT-PCR and real-time quantitative RT-PCR (qRT-PCR), and it was applied to the detection of actual samples, so as to achieve rapid detection of H9 subtype low pathogenic avian influenza.

\section{Materials and Methods}

\subsection{Materials}

\subsubsection{Virus and Samples}

The viruses used in the experiments (H9 subtype, influenza virus, H3N2 subtype influenza virus, H4N2 subtype influenza virus, H6N2 subtype influenza virus), and clinical samples were all preserved in our laboratory.

\subsubsection{Instruments and Reagents}

Real time fluorescence quantitative RT-PCR: Roche's production of LC4800, Real-time, RT-PCR, System;

Digital RT-PCR: QX200Droplet, Generator, PX1, RT-PCR, Sealer, S1000, Thermal, Cycler, QX200, Droplet, Reader, Plate produced by Bole company;

One step prime script RT-PCR Kit (perfect real time) Kit: from treasure biological company;

One-step RT-ddRT-PCR kit for probes Kit: bought from Bole company.

\subsection{Method}

\subsubsection{Primers and Probes (See Table 1)}

\subsubsection{Extraction of RNA}

TaKaRa RNA extraction kit was used to extract H9 virus RNA. After extraction, RNA was used as the original template and diluted $10^{-1}, 10^{-2}, 10^{-3}, 10^{-4}, 10^{-5}$, $10^{-6}, 10^{-7}, 10^{-8}$ imes, respectively, and stored in $-20^{\circ} \mathrm{C}$ refrigerator.

\subsection{3. dRT-PCR-Determination of Annealing Temperature}

The reaction liquid is configured according to Table 2, and the annealing temperature of the amplification reaction is determined according to the reaction conditions set out in Table 3, respectively, between $-50^{\circ} \mathrm{Cand}-60^{\circ} \mathrm{C}$. 
Table 1. The sequence of H9 PRIMERS AND Taqman probe.

\begin{tabular}{cc}
\hline Name & Sequence \\
\hline Forward primer & 5'-CCATTGRACATRGCCCAG-3' \\
Reverse primer & 5'-CYATTTATTCGACTGTCGCCTC-3' \\
TaqMan probe & 5'-(FAM)-FRGAAGGCAGCRAACCCCATTGCAAP-(TAMRA)-3' \\
\hline
\end{tabular}

Table 2. The reaction system of digital RT-PCR assay.

\begin{tabular}{cc}
\hline Reagents & Volume \\
\hline 2X One-Step RT-ddRT-PCR supermix & $10 \mu \mathrm{L}$ \\
25 mM manganese acetate solution & $0.8 \mu \mathrm{L}$ \\
RT-PCR Forward Primer $(10 \mathrm{uM})$ & $0.4 \mu \mathrm{L}$ \\
RT-PCR Reverse Primer $(10 \mathrm{uM})$ & $0.4 \mu \mathrm{L}$ \\
TaqMan Probe & $0.4 \mu \mathrm{L}$ \\
DEPC $\mathrm{H}_{2} \mathrm{O}$ & $6 \mu \mathrm{L}$ \\
RNA & $2 \mu \mathrm{L}$ \\
Total & $20 \mu \mathrm{L}$
\end{tabular}

Table 3. The reaction conditions of digital RT-PCR assay.

\begin{tabular}{ccc}
\hline Temperature & Time & Cycle \\
\hline $60^{\circ} \mathrm{C}$ & $30 \mathrm{~min}$ & \\
$95^{\circ} \mathrm{C}$ & $5 \mathrm{~min}$ & \\
$94^{\circ} \mathrm{C}$ & $20 \mathrm{~s}$ & 6 \\
$60^{\circ} \mathrm{C}$ & $35 \mathrm{~s}$ & \\
$94^{\circ} \mathrm{C}$ & $20 \mathrm{~s}$ & 36 \\
$50^{\circ} \mathrm{C}-60^{\circ} \mathrm{C}$ & $35 \mathrm{~s}$ & \\
$98^{\circ} \mathrm{C}$ & $10 \mathrm{~min}$ & 1 \\
$12^{\circ} \mathrm{C}$ & $\infty$ & 1 \\
\hline
\end{tabular}

\subsection{4. qRT-PCR Test}

A qRT-PCR method for the determination of $\mathrm{H} 9 \times 10^{0}, 10^{-1}, 10^{-2}, 10^{-3}, 10^{-4}, 10^{-5}$, $10^{-6}, \mathrm{H} 3 \mathrm{~N} 2, \mathrm{H} 4 \mathrm{~N} 2, \mathrm{H} 6 \mathrm{~N} 2, \mathrm{NTC}\left(\mathrm{H}_{2} \mathrm{O}\right)$ amplification curve and $\mathrm{Ct}$ value, repeated three times.

\subsection{5. dRT-PCR Test}

The sensitivity and specificity of the dRT-PCR method for H9 were determined, wherein the specificity test was controlled by H3N2, H4N2, H6N2, according to Table 2 reaction system $(20 \mu \mathrm{L})$ and reaction conditions (annealing temperature 2.2.3, temperature determined by Table 3 ). 


\subsubsection{Detection of Samples}

Select the appropriate samples and validate them using the above two methods (2.2.4, 2.2.5).

\subsubsection{Data Analysis}

After the amplification of dRT-PCR reaction, Droplet Reader was used to read the results, and to judge the presence of amplified droplets as the basis, and to analyze the. qRT-PCR response data, and to determine the result by looking at the amplification curve and $\mathrm{Ct}$ value.

\section{Results and Analysis}

\subsection{Determination of Annealing Temperature at dRT-PCR}

The amplification of temperature at $50^{\circ} \mathrm{C}-60^{\circ} \mathrm{C}\left(0.5^{\circ} \mathrm{C}\right)$ was measured. The results showed that when the annealing temperature was $59^{\circ} \mathrm{C}$, the amplification reaction could occur. Therefore, the annealing temperature of the primer was $59^{\circ} \mathrm{C}$.

\subsection{Sensitivity Analysis}

\subsubsection{Sensitivity of qRT-PCR}

H9 RNA will be diluted 10 times, were detected by qRT-PCR. The results showed that (see Figure 1): the concentration of template $10^{0}, 10^{-1}, 10^{-2}, 10^{-3}$, $10^{-4}, 10^{-5}, 10^{-6}$ in the range of 7 orders of magnitude, the growth curve of qRT-PCR were "S" type, and the exponential growth period of qRT-PCR curve are almost parallel, reflect the amplification efficiency of similar template $\times 10^{-5}$, $10^{-6} \mathrm{Ct}$ value is greater than 28 , similar to the blank control group, $\mathrm{Ct}$ value, so the detection sensitivity for the original template $\times 10^{-4}$.

\subsubsection{Sensitivity of dRT-PCR}

The H9 RNA template 10 times dilution series, dRT-PCR detection. Read each dilution was amplified from Figure 2 can droplet number, with increasing dilution the amplification gradually decreased from $10^{0}$ to $10^{-4}$. The number of amplified were $3980,406.3,60.4,8.9,2.2$ copies $/ \mu \mathrm{L}$, from the $10^{-5}$ dilution started close to the amount of amplification, and in $0-1$ copies $/ \mu \mathrm{L}$, although the content of the $\mathrm{H} 9$ template is very few, but can still detect pathogens.

\subsection{Specificity Analysis}

\subsubsection{The Specificity of qRT-PCR}

H9 were extracted from H3N2, H4N2, H6N2, RNA, qRT-PCR were detected. The results showed that the amplification curve of H9 is " $\mathrm{S}$ " (see Figure 3), while $\mathrm{H} 3 \mathrm{~N} 2, \mathrm{H} 4 \mathrm{~N} 2, \mathrm{H} 6 \mathrm{~N} 2$ is not a typical "S" shape amplification curve showed that $\mathrm{H} 3 \mathrm{~N} 2, \mathrm{H} 4 \mathrm{~N} 2, \mathrm{H} 6 \mathrm{~N} 2$ were therefore selected primers amplification. The probe and specificity of $\mathrm{H} 9$ is good.

\subsubsection{The Specificity of dRT-PCR}

H9, H3N2, H4N2, RNA, H6N2 of the original template was shown in Figure 4, 
Amplification Curves

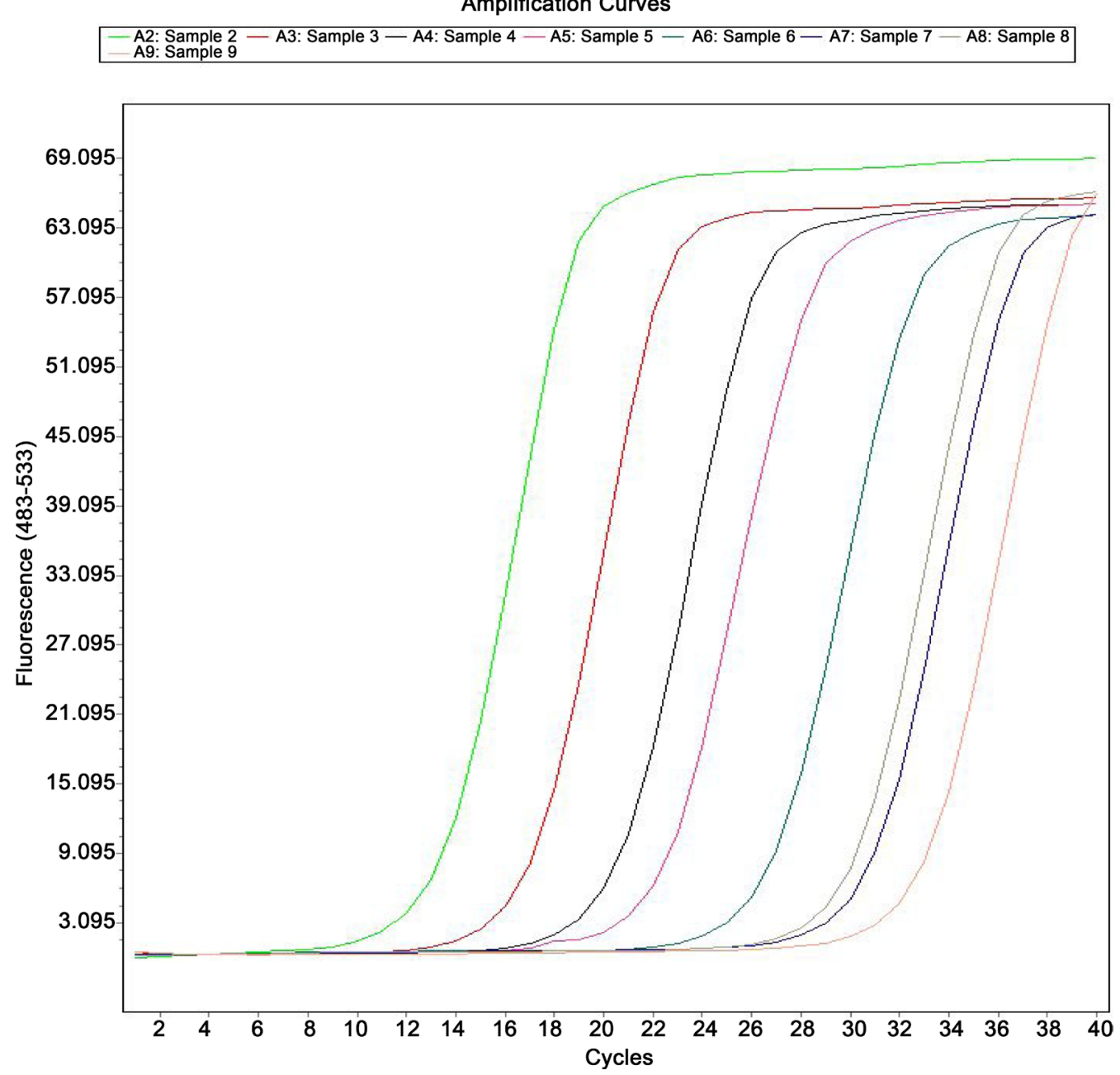

Note: Sample A2-A7 represent the original template $10^{0}, 10^{-1}, 10^{-2}, 10^{-3}, 10^{-4}, 10^{-5}, 10^{-6}$, Sample A2 is blank control.

Figure 1. Amplification plot of real-time RT-PCR assay for the detection of H9.

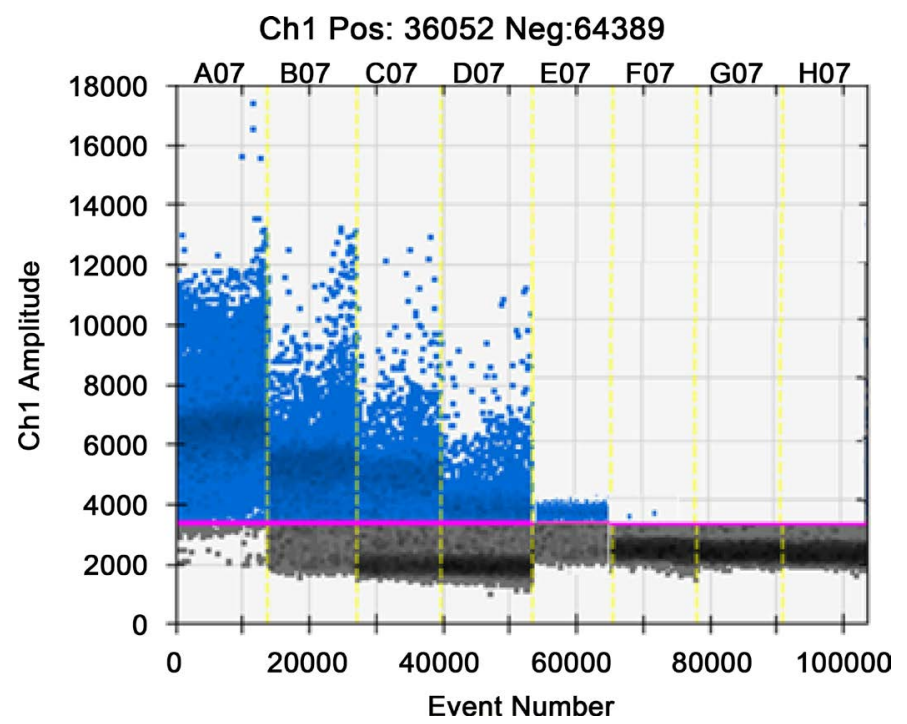

Note: A07-G07 represent the original template $10^{0}, 10^{-1}, 10^{-2}, 10^{-3}, 10^{-4}, 10^{-5}, 10^{-6}$, H07: blank control.

Figure 2. The sensitivity of digital RT-PCR assay for the detection of H9. 


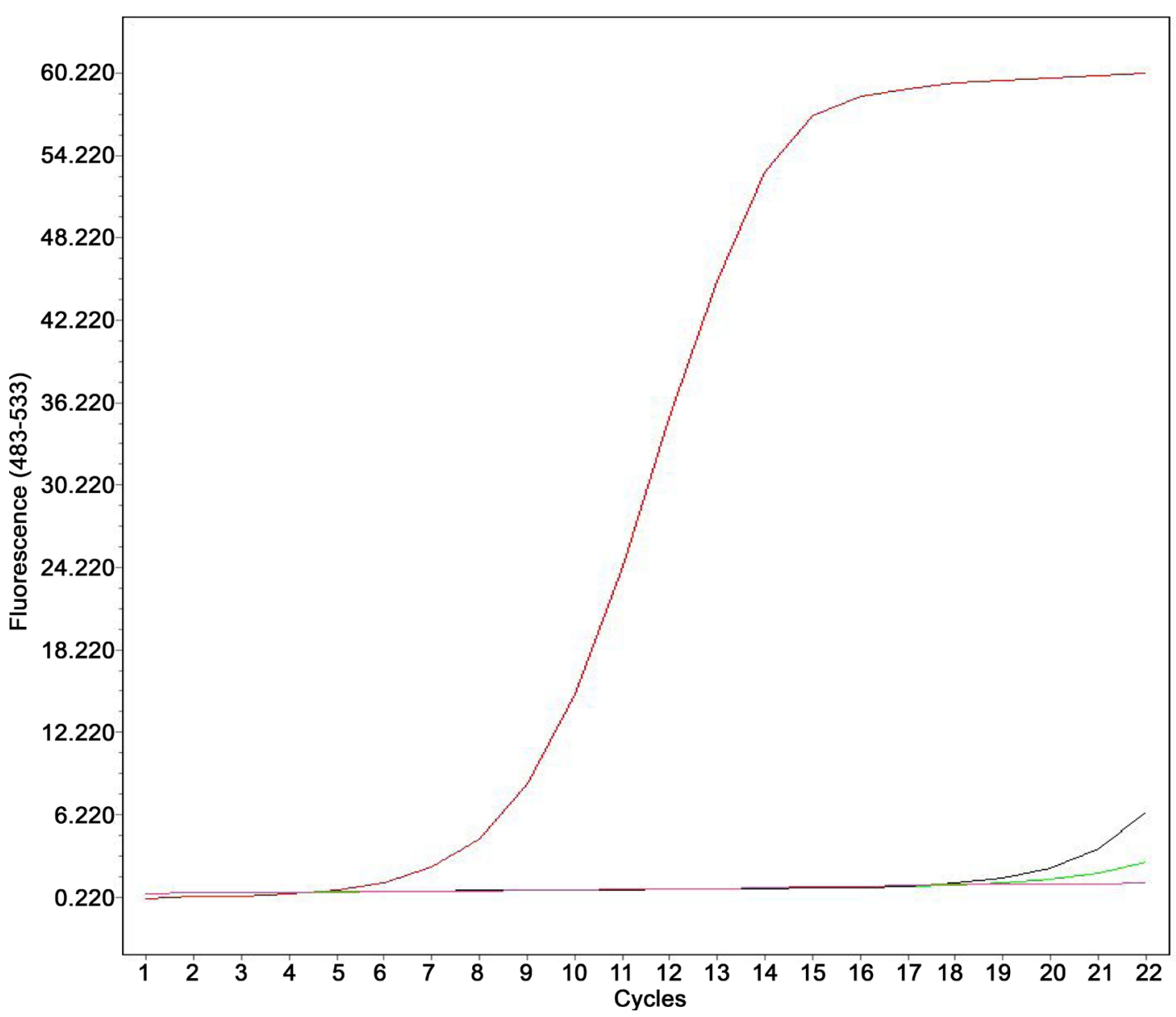

Note: Sample A2: H9 Sample A3: H3N2 Sample A4: H4N2 Sample A5: H6N2.

Figure 3. Specificity test of real-time RT-RT-PCR assay for H9.

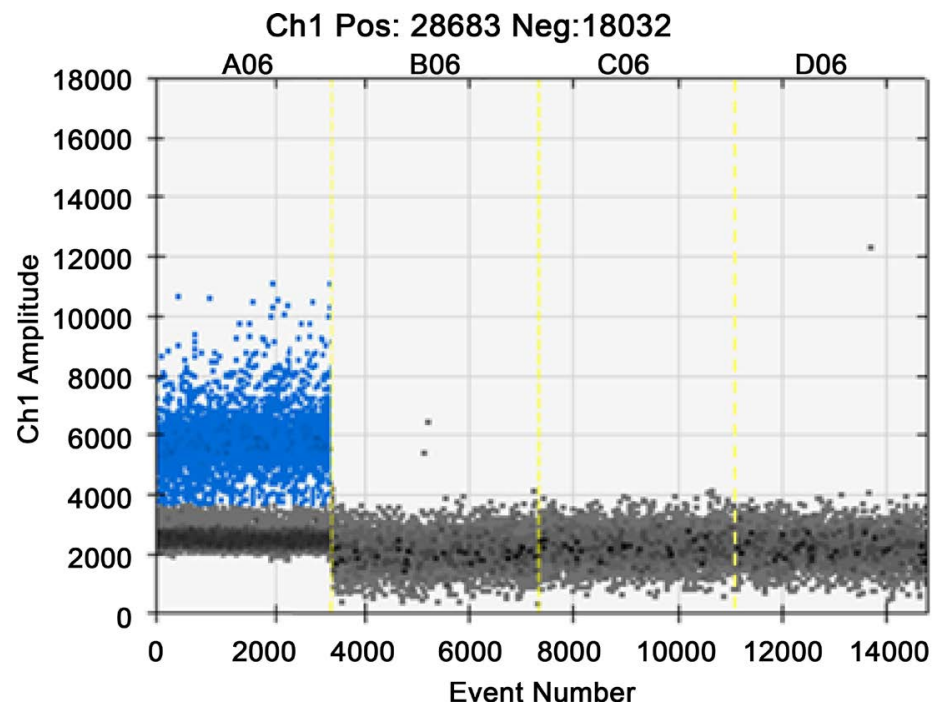

Note: A06: H9 B06: H3N2 C06: H4N2 D06: H6N2.

Figure 4. The specificity of digital RT-PCR assay for the detection of H9. 
Table 4. The repeatability of Real-time RT-PCR and Digital RT-PCR (mean \pm SE).

\begin{tabular}{ccc}
\hline Concentration & Ct Value (Real-Time RT-RT-PCR) & Number of Droplets (Digital RT-PCR) \\
\hline H9 $\times 100$ & $12.41 \pm 0.36 \mathrm{a}$ & $4026.15 \pm 172.46 \mathrm{a}$ \\
$\mathrm{H} 9 \times 101$ & $15.70 \pm 0.64 \mathrm{a}$ & $465.32 \pm 94.76 \mathrm{~b}$ \\
$\mathrm{H} 9 \times 102$ & $18.24 \pm 0.27 \mathrm{a}$ & $59.42 \pm 1.21 \mathrm{c}$ \\
$\mathrm{H} 9 \times 103$ & $21.74 \pm 0.97 \mathrm{~b}$ & $8.64 \pm 0.67 \mathrm{~d}$ \\
$\mathrm{H} 9 \times 104$ & $25.68 \pm 0.89 \mathrm{bc}$ & $3.19 \pm 1.01 \mathrm{~d}$ \\
$\mathrm{H} 9 \times 105$ & $28.4 \pm 1.08 \mathrm{c}$ & $2.74 \pm 2.28 \mathrm{~d}$ \\
$\mathrm{H} 9 \times 106$ & $30.23 \pm 1.17 \mathrm{c}$ & $3.04 \pm 3.10 \mathrm{~d}$ \\
$\mathrm{NTC}(\mathrm{H} 20)$ & $35.02 \pm 0.42 \mathrm{~d}$ & $0 \mathrm{~d}$ \\
\hline
\end{tabular}

the specificity of $\mathrm{H} 9$ is better, a large number of droplets occurred in the amplification reaction, while the other three kinds of virus $\mathrm{H} 3 \mathrm{~N} 2, \mathrm{H} 4 \mathrm{~N} 2, \mathrm{H} 6 \mathrm{~N} 2$ were only $0.23,0.15,0.27$ copies $/ \mu \mathrm{L}$, can be neglected.

\subsection{Reproducibility Analysis}

Through the 8 test dRT-PCR and qRT-PCR reproduce the reproducibility of the results obtained, as shown in Table 4. Table 4 shows, 8 small reproduction error test, the test of good reproducibility. The qRT-PCR Ct values of 8 replicates standard error smaller between 0.36 - 1.17, standard error dRT-PCR; droplet number 8 replications is less than the total droplet number (total droplet number Droplet Reader read 2000/ $\mu$ L) 2.4\%, good reproducibility.

\subsection{Clinical Samples Were Detected}

\subsubsection{Detection of Samples by dRT-PCR}

The dRT-PCR method was used to detect the sample to be detected by H9, RNA, RNA Health Organization, water as a positive control, negative control and blank control. The results showed that samples were amplified, samples containing $\mathrm{H} 9$ pathogens, see Figure 5.

\subsubsection{Detection of Samples by qRT-PCR}

The qRT-PCR method was used to detect samples with H9, RNA, RNA Health Organization, water were used as positive control, negative control and blank control. $1 \mathrm{H} 9$ and RNA 2, 3, 4 were observed in the sample of "S" type amplification curve, showed detectable H9 H9.5 in sample, see Figure 6.

\section{Discussion}

H9 subtype avian influenza is widespread and spreads rapidly, which can cause recessive infection of chicks and chickens and decrease in hen egg production.H9 subtype avian influenza virus itself on the chick mortality rate is low, but once mixed with bacteria and other infected chickens, the situation will be unable to control [6]. While the traditional PCR method is not sensitive, prone to missed detection. 


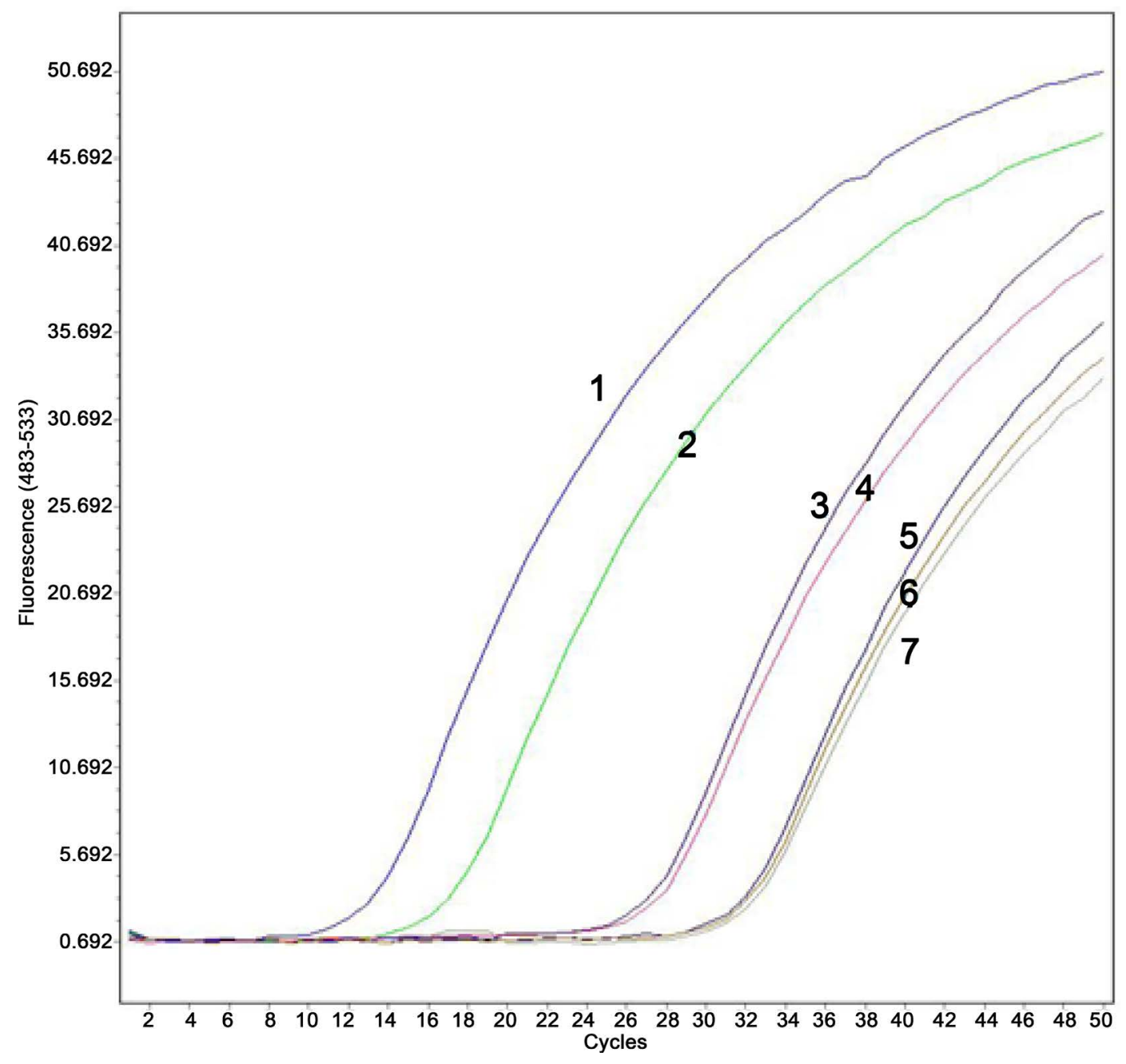

Note: 1: H9 RNA, 2 - 5: sample, 6: negative control, 7: blank control.

Figure 5. Amplification plot of real-time RT-RT-PCR samples with H9.

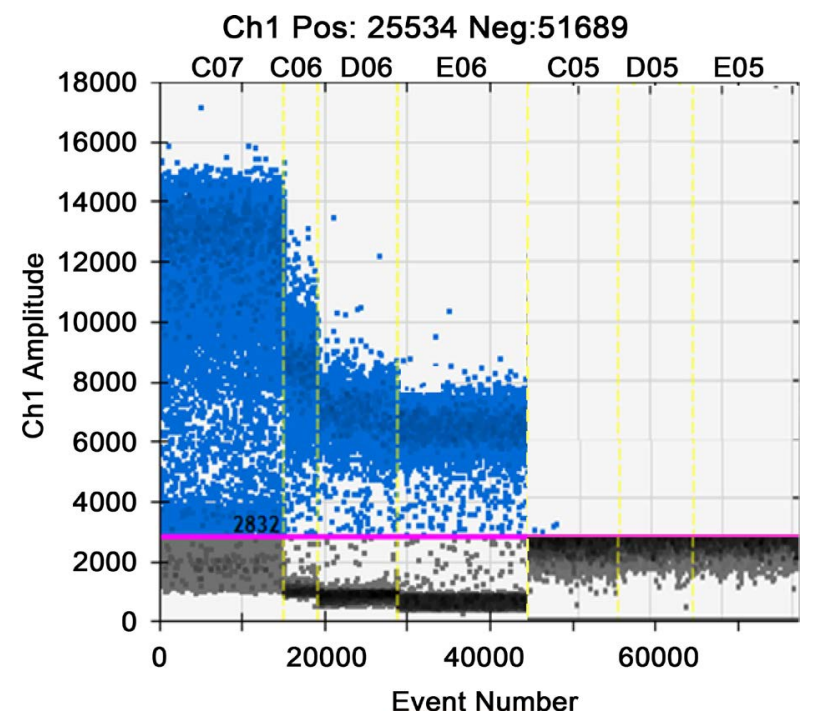

Note: C07: H9 RNA, C06-C05: sample, D05: negative control, E05: blank control.

Figure 6. Digital RT-PCR reaction for infection detection test samples with H9. 


\section{Conclusion}

In this paper, by comparison of the two methods of qRT-PCR and dRT-PCR, the following conclusions can be drawn: dRT-PCR is more sensitive than qRT-PCR and can detect the target gene in single droplet, and can detect trace pathogen, which is more widely used than qRT-PCT method. The designed primers and probes are specific and have only amplification reaction to $\mathrm{H} 9$ and can be used for daily $\mathrm{H} 9$ detection. Compared with qRT-PCR, dRT-PCR reproducibility is higher, and can be used as a confirmation method in routine testing.

\section{References}

[1] Zhou, J.P. and Liu, J. (2010) Investigation of H9 Subtype Avian Influenza Virus in Live Poultry Wholesale Market in Shanghai. Chinese Journal of Animal Infectious Diseases, 18, 31-33.

[2] Chen, A. and Zhang, Z.J. (1994) Research on Avian Influenza: Chicken I A Avian Influenza Virus Isolation and Identification of Serological. Chinese Veterinary Journal, 22, 3-5.

[3] Wu, H.Y., Li, M.Y., et al. (2010) Special Study on Molecular Epidemiology of 33 Strains of H9 Subtype Avian Influenza Virus. China Animal Quarantine, 27, 31-33.

[4] Zhan, C., Yan, L., et al. (2015) Development and Application of Digital PCR Technology. Journal of Fudan University, 42, 785-789.

[5] Lin, C.Q. and Yao, B. (2012) Advances in Digital PCR Technology. Advances in Chemistry, 24, 2415-2422.

[6] Hu, T., Shen, W.X., et al. (2013) Establishment and Preliminary Application of Fluorescent Quantitative PCR Method for H9 Subtype Avian Influenza Virus. Chinese Journal of Animal Infectious Diseases, 21, 7-13. 